\title{
A Managerial Approach on Reputational Risks in the Banking Sector under the Effects of Covid-19 Pandemic
}

\author{
Ciprian MANEA ${ }^{\star}$
}

\begin{tabular}{l}
\hline \multicolumn{1}{c}{ A R T I C L E I N F O } \\
\hline Article history: \\
Accepted March 2021 \\
Available online April 2021 \\
\hline JEL Classification \\
G21, D81 \\
Keywords: \\
Reputational risk, Bank, \\
Compliance, Financial crisis
\end{tabular}

\begin{abstract}
A B S T R A C T
The purpose of this study is to develop an effective approach to reputational risk management in Romanian banks. It is a study that develops a holistic approach to measuring and managing reputation risk. The goal of this paper is to clarify whether in times of crisis the reputation of banks suffers from an FsQCA analysis. This study explores how the causal configurations of antecedent conditions associated with the research model (remote banking applications, crisis-specific legal regulations, crisis-specific cost cuts, and innovative measures applied during this period) have a significant impact on the outcome. expected: if in times of crisis, the reputation of banks suffers.
\end{abstract}

(C) 2021 EAI. All rights reserved.

\section{Introduction}

Reputation is a dynamic phenomenon from a temporal point of view and no single indicator can be identified to statically calculate the level of risk. The purpose of effective reputation risk management may, in the future, be to help prevent the negative effects of struggling banks due to the economic context or the crisis period. Reputation is a decisive factor for a bank's profit, and reputation risk is a negative or positive deviation from the expected reputation.

This concept of expected reputation has as a starting point the public image of the bank in terms of competence, integrity and trust, which results from the perception of stakeholders. A holistic definition that would integrate the issue of reputation, identification, assessment and control of the risks to which banks are exposed in global competition is mandatory (Ogrizek, 2002).

\section{Literature review}

No uniform definition of "reputation" has been reached in the literature so far. The approach of specialists goes from a macro level that considers reputation as a resource, to a micro level that considers reputation as a social vision of the company (Fombrun, Gardberg and Barnett, 2000; Fombrun and Van Riel, 1997; Brady, 2005; Scott and Walsham, 2005).

In another approach, reputation is not seen as a process, but rather as an intangible strategic asset, through which tangible profits and increased added value could be generated - for example, higher turnover, expenses smaller operating, etc. (Little \& Little, 2000; Roberts \& Dowling, 2002).

Starting from the data of those who studied the field of reputational risk, as well as from their own practical observations, the definition of the term "reputation", which focuses on creating a potential for success and preventing failure, can be summarized as follows: Public reputation of a bank its competence, integrity and trust, which results from the perception of the stakeholder group: customers, shareholders, external creditors, employees, business partners, financial communities, competitors, rating agencies, analysts and fund managers, government authorities and regulation, interest groups, social environment, etc.

Reputational risk management in banks has become an important concern for bank management, due to the complexity and dynamism of the business environment, but also the positioning of regulators (Maghyereh and Awartani, 2014). In the last two decades, significant progress has been made internationally to improve risk management practices in financial institutions (Chortareas, Giradone, \& Ventouri, 2011). To this end, the Basel Committee on Banking Supervision has established an internationally recognized set of principles for dealing with the various risks, officially called the Basel Accord (Basel I, Basel II and Basel III). Central banks and other regulators in various countries have taken rigorous measures to implement the Basel Accords in the banking sector to strengthen their coherent risk management systems (Masood and Fry, 2012). 
There is a close correlation between a bank's reputation and its credibility. Credibility is directly linked to performance - it can be defined as the belief that the bank will achieve its strategic and / or operational objectives. "Credibility is defined as the degree to which the public considers that a change in policy has taken place, when such a change has indeed taken place. In general, it seems that reputation derives from that amount of credibility. A bank with a good reputation is therefore a credible bank" (Eskenazi 2015).

In this context, active reputation management can make a significant contribution to protecting and enhancing a bank's market value by identifying reputational risks, preventing and limiting reputational losses, and preparing measures to generate reputational gains at the same time. Reputation management can, in this process, be defined as a target process of defining, identifying, evaluating and controlling reputational risks.

\section{Research methodology}

Qualitative comparative analysis (QCA) is a research technique that aims to eliminate the gaps between qualitative and quantitative analyzes (Rihoux and Ragin, 2009). Unlike quantitative research, QCA creates the opportunity to analyze how multiple causal configurations affect an outcome (Ragin, 2014). The QCA value for this current research is based on the existence of conditions that are sufficient (but not necessary) to determine the outcome. Using coherence (analogous to correlation) and coverage (a value of effect size), QCA explains how causal configurations lead to a certain outcome (Woodside, 2010). Qualitative comparative analysis (QCA) really introduces the concept of "equifinality", based on the idea that several paths can coexist towards a desired result in a configurational research design (Fiss, 2007)

\section{Research framework}

This study explores how the causal configurations of antecedent conditions associated with the research model (remote banking applications, crisis-specific legal regulations, crisis-specific cost cuts, and innovative measures applied during this period) have a significant impact on the outcome. expected: if in times of crisis, the reputation of banks suffers. The research model (Figure 1) reflects the expected result as a linear function whose arguments are the four antecedent conditions.

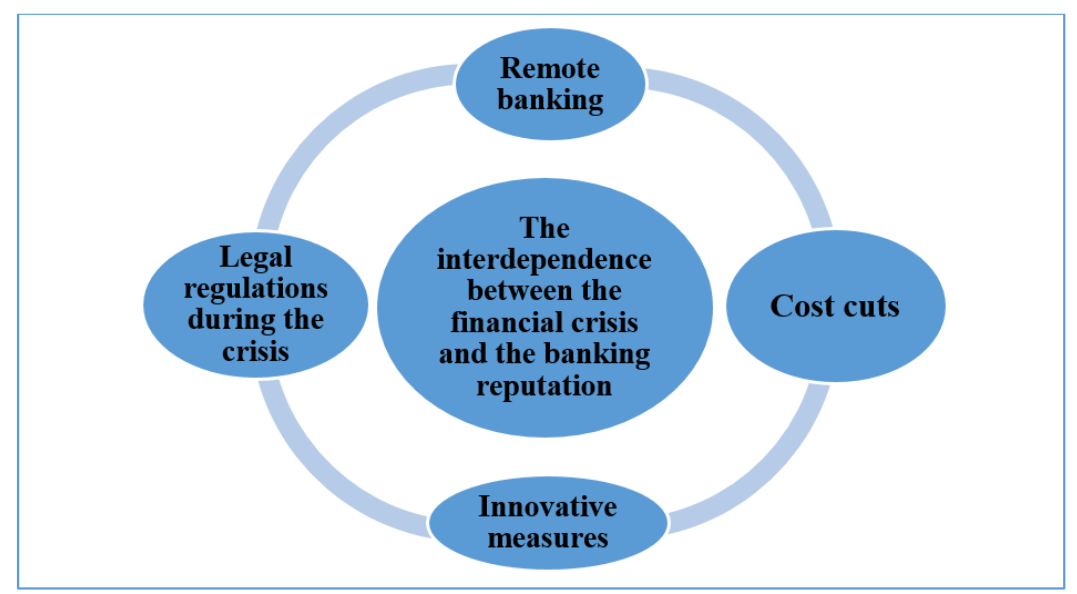

\section{Findings}

Figure 1. The conceptual model of research

The questionnaire was divided into two sections, depending on the need for a configurational approach to the result. The first four elements of the questionnaire reflect the previous conditions, being interpreted as strategies applied or observed by the respondents in the banks where they work. These are assessed by a five-point Likert scale. The fifth element highlights the result: in times of crisis, the reputation of banks suffers.

First issue tests if the banking reputation is affected in the context of new remote banking applications, which also allow the opening of new customers, without presence at the bank (Figure 2). 


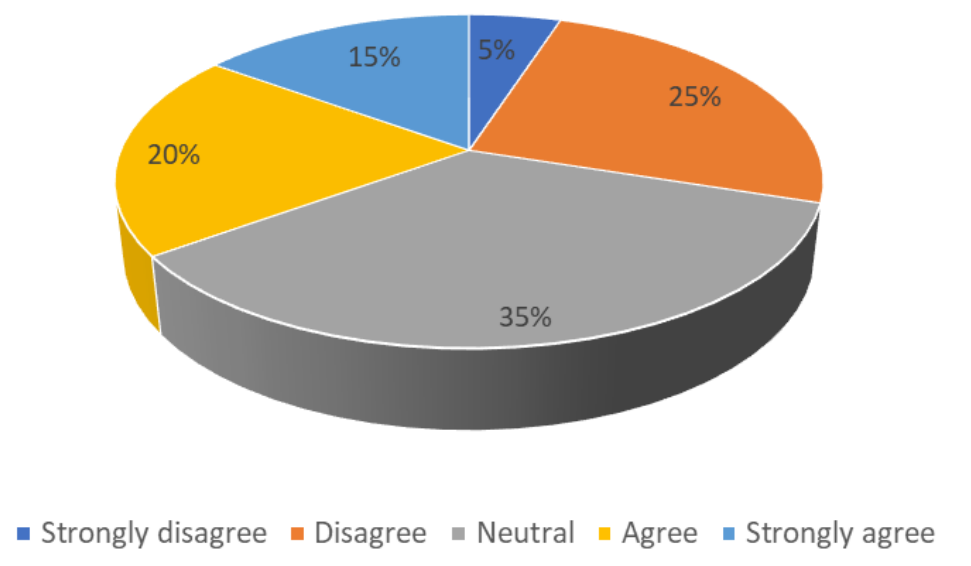

Figure 2. New remote banking applications' effect on banking reputation

This question generated quite vague answers. It is obvious that not being sure of the answer, the specialists gave largely (14 cases) the neutral answer, because they do not know how to position themselves towards the inevitable development of the distance business. Remote application development is essentially a good thing, useful for the customer, but it is important to understand the impact on the bank in terms of the risks it can generate. Extrapolating the analysis of the resulting figures, there is a slight superiority of the number of respondents who agreed with the respondents who did not agree with this idea.

The second issue investigates if the legal regulations applied during the crisis also affect the reputation of the banks or only their profitability (Figure 3).

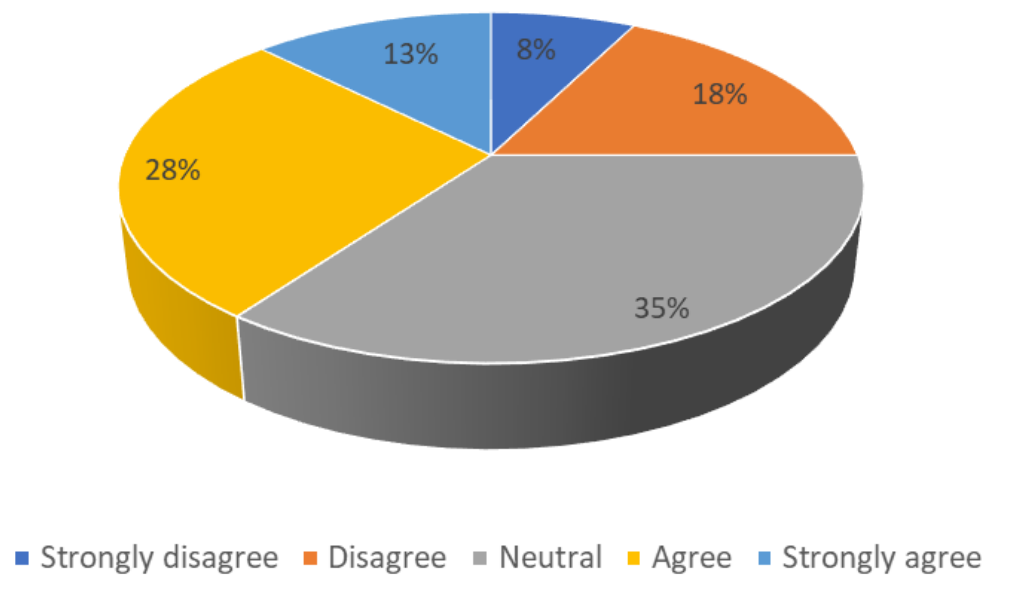

Figure 3. Legal regulations applied during the crisis and banking reputation

To the second question the situation is a little clearer, even if the number of "undecided" remained the same: 14. However, beyond those who did not want to position themselves here either (they may be the same respondents), those who still cannot clearly express what the current crisis will bring, in the agreement area, 11 specialists consider that in the periods of the crisis is also affecting the reputation of banks, not just profitability.

There should be no direct link, but even if there are several stages that take place in each crisis, I believe that this crisis will have an impact on the area of reputation. The financial crisis, which was caused by the coronavirus pandemic, determined in the first stage the application of social measures to try to counteract possible negative effects. However, as in every crisis, the stage of collapse of financial indicators will follow, and in the banking field it is reflected in a first stage in the segment of non-performing loans, caused by the difficulties that companies and the population will go through.

Subsequently, by passing these loans in the off-balance sheet category, i.e. by marking the loss from a financial point of view, the financial impact will be direct on the banks and in these conditions, the banking system will report losses for the next period.

Under these conditions, certain legal measures will be applied, or implemented by national and international regulators; The specialists who participated in this questionnaire expect that the applied measures will have a direct impact on the reputation of the banks, not only on their financial performance. 
Third issue reflects the perception of respondents regarding the impact of cost cuts that banks apply in times of economic crisis on their reputation (Figure 4).

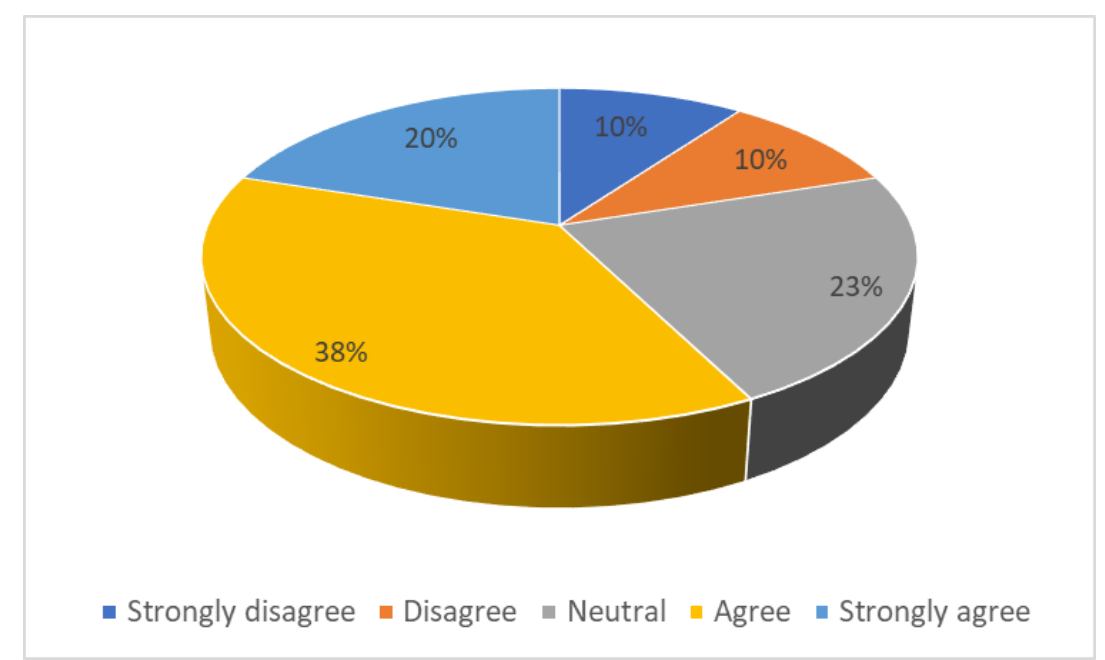

Figure 4. Impact of cost cuts that banks apply in times of economic crisis on banking reputation

It is the first question to which the opinion of the specialists is clear - in the period of crisis the banks apply cost cuts, and they affect their reputation; more than half of the respondents expressed an agreement or a total agreement in this regard.

The first cost cuts are reflected primarily in salaries, being known that about half of a bank's expenses represent the salary fund. There are two categories of cuts - those related to dismissals and those related to the actual reduction of salaries, or those resulting from the cancellation of performance reward bonuses. Against the background of uncertainties, the professional performance of employees decreases; additional stress factors caused by possible layoffs are added; in addition, the best employees, rewarded for exceeding the objectives, no longer have the opportunity to collect bonuses; all these causes determine a negative attitude, which is immediately reflected in the relationship with customers and in the image of the bank in the business environment.

There are other cost cuts: those related to the modernization of headquarters, high-performance software or outsourcing of certain activities. All these situations are reflected step by step in the quality level of the services offered by a bank, and all these are reflected in the alteration of the reputation.

Fourth issue addresses the following question: Periods of economic crisis represent for banks, more a risk than an opportunity to increase their reputation, even if innovative measures can be applied? (Figure 5)

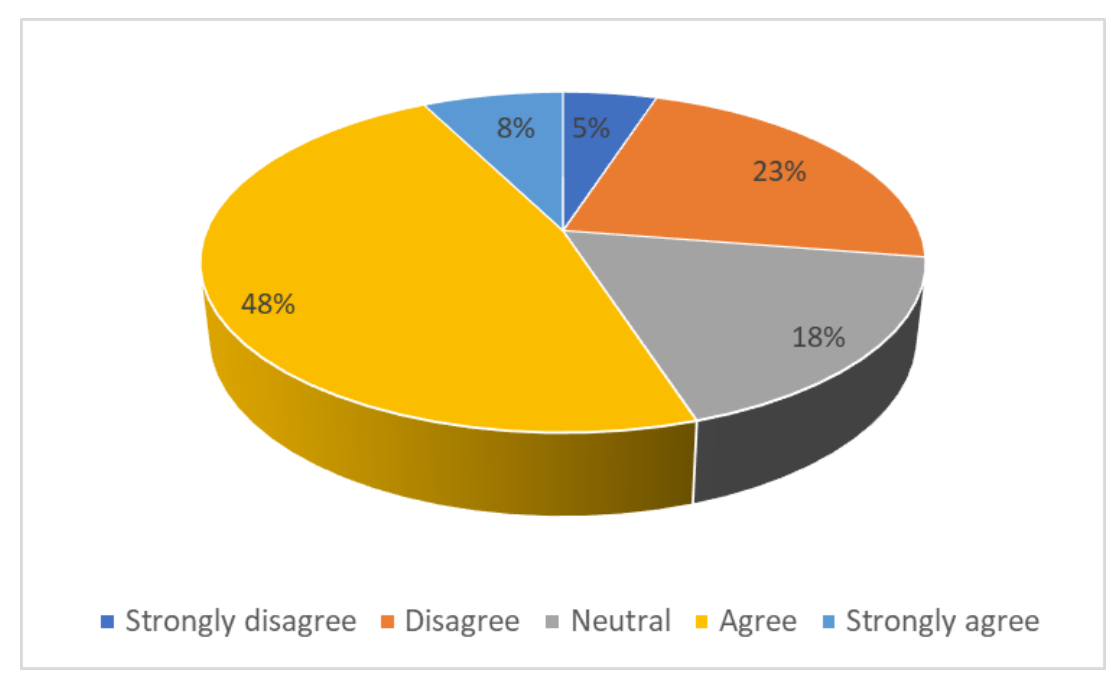

Figure 5. Risk vs opportunity perception of economic crisis

The answers are becoming more relevant and eloquent. We tried to understand if the periods of crisis represent a risk or an opportunity. Compliance employees who responded to this questionnaire have a risk profile, and their approach is prudent. Most responded that a period of crisis is a risk for the bank and not an opportunity.

Probably the answers of some employees from the bank's business area (sales, sales, marketing, etc.) would have generated other answers, either more optimistic or with an orientation towards opportunity. I 
also intentionally inserted the possibility of applying innovative measures, which would allow the possibility of the performers to obtain a competitive advantage in times of crisis, but the answers were quite clear; It is said that in the pre-storm periods, when the wind starts to blow, most look for a shelter, while the bravest identify the opportunity to build a windmill. Most Compliance employees have a risk profile, but these employees generally have extensive experience in several areas of the bank such as auditing, permanent control, but also commercial. Even if they understood the opportunity of possible areas of innovation, the final opinion is that periods of crisis represent a risk on the reputation area of a bank.

Fifth item reflects the outcome: the crisis affects the reputation of banks (Figure 6).

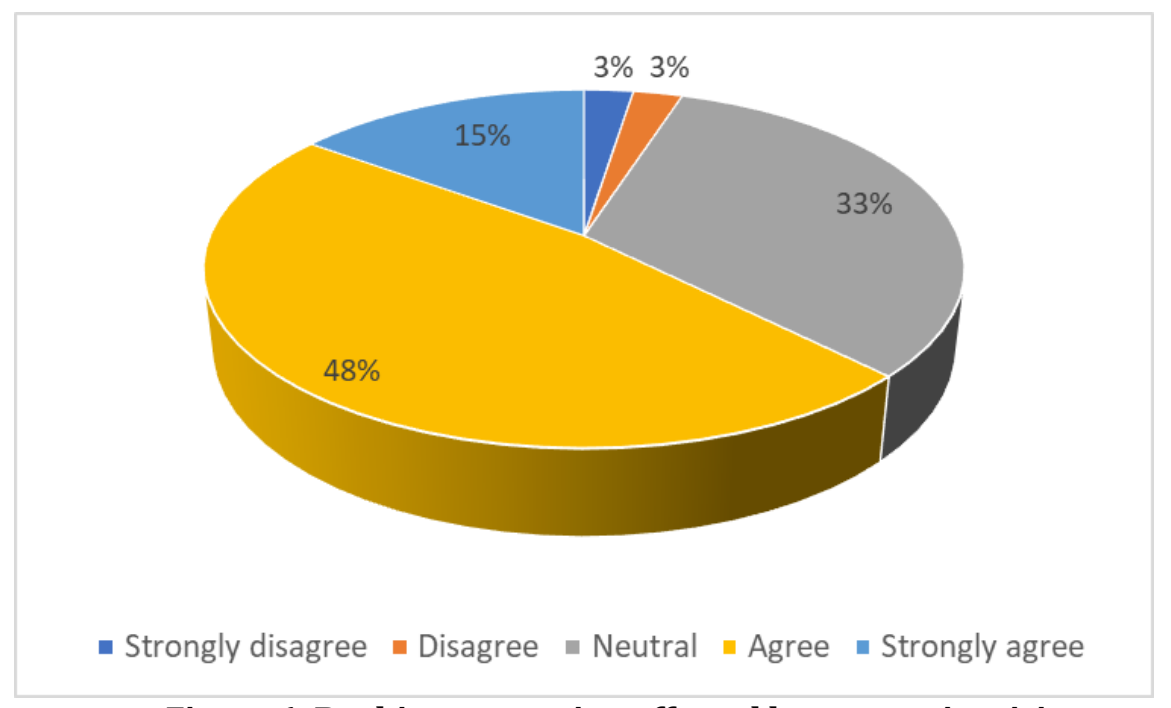

Figure 6. Banking reputation affected by economic crisis

The answer to this fifth item is in fact the final conclusion of this questionnaire - that in times of crisis, the reputation of banks is affected. Only 2 respondents expressed disagreement and total disagreement; even if 13 answers are neutral, the other 23 answers given by experts in the field, which represent $57.5 \%$, highlight the reality of banking in times of crisis: the reputation of banks is affected

We will further analyze from a technical point of view, through the FsQCA analysis, the way in which these multiple causal configurations affect the obtained result and if this result is relevant and validated.

\section{Calibration process}

The research project focuses on the assumption that the relationships between the antecedent conditions used in this study are asymmetric, because the causes of the risks are diverse. Therefore, alternative combinations of causal conditions may lead to the result.

We transformed the values for the causal conditions (ebanking, legal regulations in time of crisis legalregulations, cost cuts - costcut and possible applicable innovative measures - innovmeasures) and the result (interdependence between periods of financial crisis and banking reputation - negativeeffects) into fuzzy-set scores from 0 (definitely not) to 1.00 (definitely yes).

Table 1 reflects the calibration of the causal conditions and the result, taking into account their values from the specific evaluation scale.

Table 1. Calibration process

\begin{tabular}{ccc}
\hline The point of the scale & Fuzzy set value & Membership \\
\hline Completely agree / Most likely & 1 & Fully in \\
Agree / Probably & 0.75 & More in than out \\
I do not approve or disapprove / & 0.5 & Cross-over (neither in nor out) \\
Possible & 0.25 & More out than in \\
I don't agree / Probably not & 0 & Fully out \\
I completely disapprove / Definitely not & Source: adapted from Ragin, C. C. (2014). The comparative method: Moving beyond qualitative and quantitative \\
strategies. Berkely and Los Angeles, USA: University of California Press.
\end{tabular}

Aebi, Sabato and Schmid (2012) conducted a study on risk management, corporate governance and bank performance during the 2007-2008 financial crisis. They mainly investigated the impact of risk management related to corporate governance mechanisms on banks' performance. The performance of the selected banks was measured by the return on equity, together with certain standard variables of corporate 
governance, such as ownership, size of the board of directors and its independence. They indicate that effective risk governance played an important role in achieving performance during 2008, indicating that effective risk management is directly linked to the performance of selected banks.

This paper seeks to identify the answer to the question: "the reputation of banks is affected during the financial crisis" through the fsQCA methodology, investigating the views of those directly involved. The questionnaire was conducted to see the views of Compliance experts (40 employees from 12 top banks).

The definition of fuzy-set values for the preceding conditions is in accordance with the same rule for calibrating the result, reflecting the logic of the constructions in the configurational design approach.

The first stage of the analysis aims at combining the conditions that are sufficient to obtain the result. It examines whether a causal prescription of the conditions is always present when the result is present.

We continued the analysis of the consistency and XY plot scoring scores of the vague set. The visual representation of the cases on the XY graph demonstrates: the antecedent conditions are sufficient to obtain the result, due to the positioning of most cases above the diagonal of the graph (Figure 7).

The XY plan shows whether a specific condition is necessary or sufficient to obtain the result, emphasizing how consistent a given condition is, with the statement that it is a necessary or sufficient condition. In addition, the XY plot provides graphical information on how empirically relevant the research proposal is.

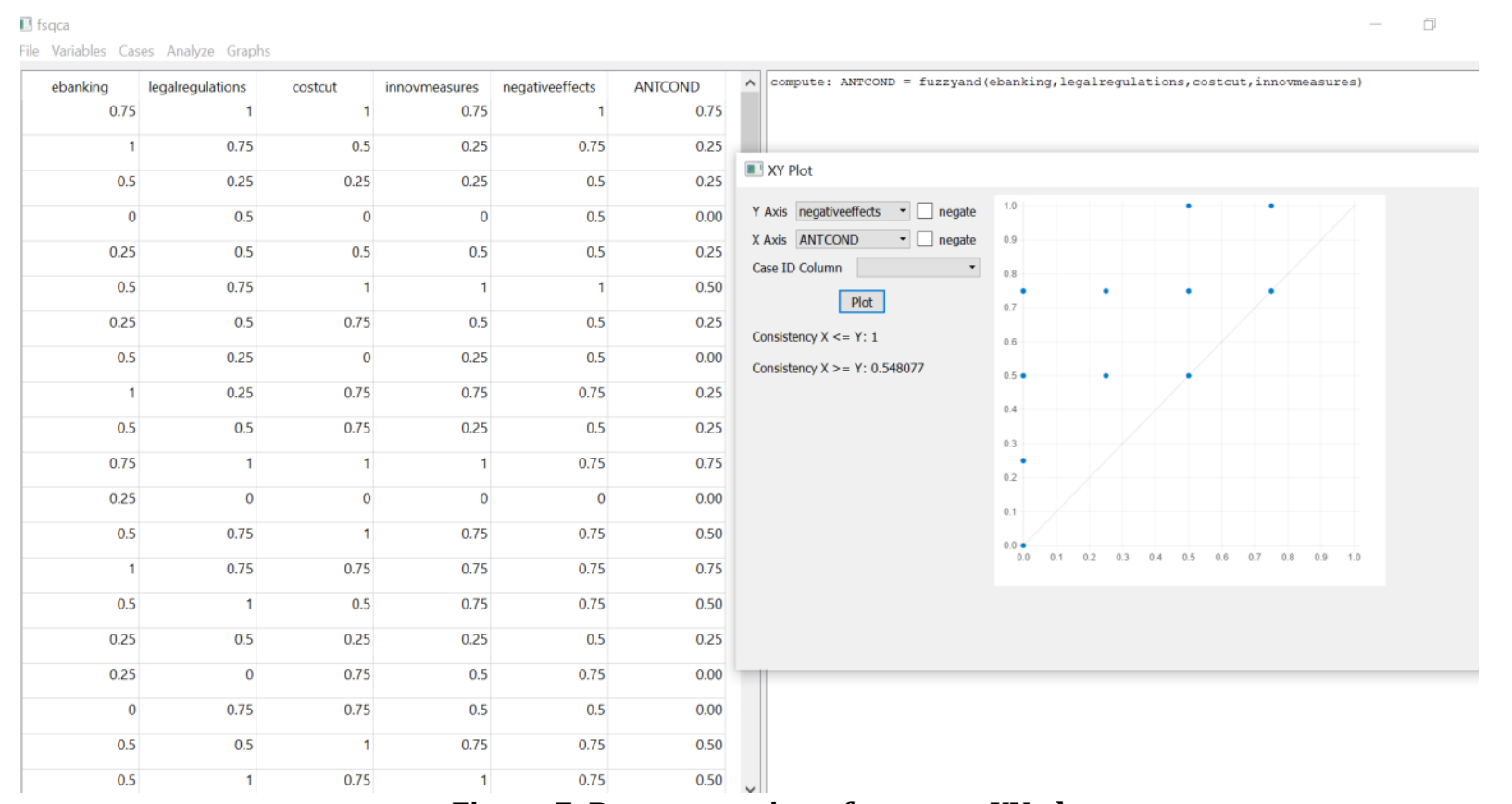

Figure 7. Representation of cases on XY plot

Source: fsQCA software output

The consistency score outlined by the complex solution, provided by Quine-McCluskey algorithm (the extent to which a causal combination leads to a result) is 0.92 (Table 2). The high consistency value reported by the XY plane indicates that the combination of antecedent conditions is sufficient to obtain the result. Although the values of consistency and coverage area suggest causality in this research project, determining causality requires the interpretation of configurations using truth table analyzes.

Table 2. Complex solution

\begin{tabular}{|c|c|c|c|}
\hline \multicolumn{4}{|c|}{$x+\frac{1}{2}$} \\
\hline Complex solution & Raw coverage & $\begin{array}{c}\text { Unique } \\
\text { coverage }\end{array}$ & Consistency \\
\hline costcut $*$ innovmeasures & 0.75 & 0.16 & 0.92 \\
\hline ebanking*legalregulations*innovmeasures & 0.59 & 0.02 & 1 \\
\hline $\begin{array}{c}\sim \text { ebanking* } \sim \text { legalregulations* }{ }^{*} \sim \text { costcut }^{*} \\
\sim \text { innovmeasures }\end{array}$ & 0.29 & 0.06 & 0.88 \\
\hline \multicolumn{4}{|c|}{$\begin{array}{ll} & \text { Solution coverage: } 0.86 \\
\end{array}$} \\
\hline \multicolumn{4}{|c|}{ Solution consistency: 0.92} \\
\hline
\end{tabular}

\section{Conclusions}

Reputation is determined not only by performance, but also by the external perception of the public and stakeholders. Therefore, efforts must be made to improve external understanding and reduce the 
asymmetry of information between a bank and stakeholders: the greater the asymmetry, the more relevant the role that reputation plays in the success of the activity.

Banks, as organizations, have sought to identify the best ways to create the most effective structure for reputational risk management. This trend is likely to accelerate, as more managers understand that while the compliance function tends to become routine, the risk function needs to become strategic, with one eye on identification and the other on risk management. in order to adapt banking strategies.

A bank's reputation is affected by the business decisions and performance generated by decision makers. Managerial implications of this study are multiple. First, from the financial performance perspective, shareholders, investors, creditors and many other stakeholders primarily consider financial performance when evaluating a bank's reputation.

Second, from quality and innovation perspective, the decision of banks to adhere to quality standards is important for improving its reputation. Banks that differentiate themselves from the competition through innovative processes and unique niche products tend to have a strong name recognition and increase their reputation. Third, from social responsibility perspective, banks with strong ethical policies are more reliable in the eyes of stakeholders. The active promotion of social responsibility and environmental protection programs contributes to creating a reputation as a "safety net" that reduces risk. Fourth, from the resilience capability, stakeholders are closely monitoring how the bank responds to difficult situations. Any action during a crisis can ultimately affect the bank's reputation.

The main limitation of the study is represented by the convenience sample used in the research process. Thus, the findings cannot be generalized to the entire banking system. Further research will replicate this model, using a structural equation modelling framework.

\section{References}

1. Aebi, V., Sabato, G. and Schmid, M., 2012. Risk management, corporate governance, and bank performance in the financial crisis. Journal of Banking and Finance, 36(12), pp. 3213-3226.

2. Brady, A. (2005). The seven elements of reputation management. Corporate Responsibility Management, 1, $12-13$.

3. Chortareas, G., Giradone, C. and Ventouri, A., 2012. Bank supervision, regulation, and efficiency: evidence from the European Union. Journal of Financial Stability, 8(4), pp.292-302.

4. Eskenazi, M. 2015. "Reputation and Credibility for Central Banks: A Brief Literature Review." Internal document of the Europe an Central Bank.

5. Fiss, P. C. (2007). A set-theoretic approach to organizational configurations. Academy of Management Review, 32(4), 1180-1198.

6. Fombrun, C. J. (1996). Reputation: Realizing value from the corporate image. Boston, MA: Harvard Business School Press.

7. Fombrun, C. J., Gardberg, N. A., \& Barnett, M. L. (2000). Opportunity platforms and safety nets: Corporate citizenship and reputational risk. Business and Society Review, 105, 85-106.

8. Fombrun, C. J., \& Van Riel, C. (1997). The reputational landscape. Corporate Reputation Review, 1, 5-13.

9. Little, P. L., \& Little, B. L. (2000). Do perceptions of corporate social responsibility contribute to explaining differences in corporate price-earnings ratios? A research note. Corporate Reputation Review, 3, 137-142.

10. Maghyereh, A.I. and Awartani, B., 2014. The effect of market structure, regulation, and risk on banks efficiency. Journal of Economic Studies, 41(3), pp.405-430.

11. Masood, O. and Fry, J., 2012. Risk management and Basel-Accord-implementation in Pakistan. Journal of Financial Regulation and Compliance, 20(3), pp.293-306.

12. Ogrizek, M. (2002). The effect of corporate social responsibility on the branding of financial services. Journal of Financial Services Marketing, 6, 215-228

13. Ragin, C. C. (2014). The comparative method: Moving beyond qualitative and quantitative strategies. Berkely and Los Angeles, USA: University of California Press.

14. Rihoux, B., \& Ragin, C. C. (2009). Configurational comparative methods: Qualitative comparative analysis (QCA) and related techniques. Thousand Oaks, CA: Sage. 